\title{
Evaluation of the Outcome of Patients with Papillary Thyroid Carcinoma with Surgical Intervention
}

\author{
Sumon Rahman Chowdhury ${ }^{1^{*}}$ \\ Yarmus Khan ${ }^{2}$ \\ Aktar Kamal ${ }^{3}$ \\ Abu Hena Mostafa Kamal ${ }^{4}$ \\ Mujibul Huq Talukder ${ }^{5}$
}

'Department of Diabetes, Endocrinology \& Metabolism Chittagong Diabetic General Hospital Chittagong, Bangladesh.

${ }^{2}$ Department of Breast and Thyroid Surgery Shandong Provincial Hospital Shandong University, Jinan, China.

${ }^{3}$ Department of Nephrology Shandong Provincial Hospital Shandong University, Jinan, China.

${ }^{4}$ Department of Biochemistry University of Science and Technology Chittagong (USTC) Chittagong, Bangladesh.

${ }^{5}$ Department of Anatomy BGC Trust Medical College Chittagong, Bangladesh.

\section{*Correspondence to:}

Dr. Sumon Rahman Chowdhury Senior Medical Officer

Department of Diabetes, Endocrinology \& Metabolism Chittagong Diabetic General Hospital

Chittagong, Bangladesh.

Mobile : +8801670393031

Email: sumonrahman79@yahoo.com

\begin{abstract}
Background : Papillary Thyroid Carcinoma (PTC) is the most common form of well differentiated thyroid cancer, and constitutes $1 \%$ of all solid tissue cancers with a female predominance and surgical intervention helps in removal of the cancer. Methods: A retrospective data analysis was done among 70 papillary thyroid carcinoma patients who had undergone radical thyroidectomy with or without selective lymph node excision in the Department of Breast and Thyroid Surgery at Shandong Provincial Hospital from 2005 to 2012. Results: The study showed a female predominance with a mean age 43.81years. $71.4 \%$ cases presented with lymphadenopathy and out of 70 patients, 16 had previous thyroid hormone dysfunction. Radical Thyroidectomy with selected lymph node excision was done in $77.1 \%$ cases and the rest had undergone only Radical Thyroidectomy. $44.3 \%$ of the tumor was $<1 \mathrm{~cm}$ in longest diameter, $58.6 \%$ cases had no lymph node metastasis and $38.6 \%$ cases had central lymph node metastasis. Mean survival after surgical management was 5.56 years with a standard deviation of 2.64 years. Only in 4 cases operative or postoperative complications were observed and in a single case we needed to perform reopen surgery. Mean hospital stay was 11 days with a standard deviation of 5 days. Distant metastasis was observed only in 2 cases and correspondingly died after 1 year. Radio ablation by using radioactive Iodine $\left(\mathrm{I}^{131}\right)$ was required in 5 patients and $88.6 \%$ required thyroid hormone replacement after surgery. Conclusion: So, surgical management is safe and results in an increased survival with possibility of cure in patients with papillary thyroid carcinoma.
\end{abstract}

Key words: Papillary Thyroid Carcinoma (PTC); Recurrence; Surgical excision; Lymph nodes; Metastasis.

\section{INTRODUCTION}

$1 \%$ of all solid organ malignancies are thyroid carcinomas and in majority of cases are cured by adequate surgical management ${ }^{1}$. PTC represents between $85 \%$ and $90 \%$ of thyroid cancers encountered in almost any thyroid surgery practice ${ }^{2}$. More than $95 \%$ of all thyroid cancers arise from thyroid follicular cells, which consist of four histological types: Papillary (85\%), Follicular (11\%), Hurthle cell (3\%), and Anaplastic $(1 \%)^{3}$. Little evidence has been known about the epidemiology of rare histological types. PTC is incidentally high and has been continually increasing in the past few decades in the countries from East Asia and also in the West ${ }^{4}$. 
Quite different approaches have been adopted in different parts of the world regarding management of PTC. These approaches have been debated for decades in the context of prolonged longterm survival and possibilities of higher complication rates with more extensive operation. Total or near total thyroidectomy remains the main surgical option in Western countries ${ }^{5}$. In Asia total or near total thyroidectomy is not the main option ${ }^{6}$. For more than $1 \mathrm{~cm}$ unilateral thyroid carcinoma ATA guidelines recommend total or near-total thyroidectomy but in China, total or near-total thyroidectomy is recommended for $>4 \mathrm{~cm}$ unilateral thyroid carcinoma, and lobectomy for $<1 \mathrm{~cm}$ unilateral thyroid carcinoma. If the tumor size is within 1-4 cm, both surgical methods above could be applied ${ }^{7}$.

It is obvious that, large extent surgery will result in greater tumor resection, but will increase the rate of complications. Significantly improved recurrence and survival rate was observed for tumors $>1.0 \mathrm{~cm}$ on a multivariate study of over 50,000 patients with PTC found with total thyroidectomy and the 10 -year survival rate was $98.4 \%$ for total thyroidectomy and $97.1 \%$ for lobectomy. So it is pointed out that the modest outcome benefit must be weighed cautiously against the potential complications after total thyroidectomy ${ }^{8}$.

Surgeon's experience also highly correlated with the rate of complications, but $86 \%$ PTC surgeries were not operated by experts ${ }^{9}$. In the United States, $50 \%$ of PTC were operated by surgeons who performed fewer than five thyroidectomies every year ${ }^{10}$. So, it is important to emphasize that the extent of thyroidectomy should be tailored not only to the patient's risk group and operative findings, but also to the progress of the specific surgery, particularly if the contralateral lobe is not involved by cancer. If unilateral thyroidectomy was completed without injuring recurrent laryngeal nerves and parathyroid glands, then contralateral thyroid surgery can be safely contemplated. If unilateral thyroidectomy was unsuccessful, elective contralateral lobe resection and Central Neck Dissection (CND) should be preferred because of the potential occurrence of recurrent laryngeal nerve paralysis and permanent hypothyroidism ${ }^{11}$.

In this study, our main objective was to see the outcome of patients having surgical intervention for PTC and to assess the survival rate and future complications.

\section{MATERIALS AND METHODS}

This is a retrospective data analysis of thyroid swelling operated in the Department of Breast and Thyroid Surgery in Shandong Provincial Hospital from 2005 to 2012, diagnosed as papillary thyroid carcinoma histopathologically afterwards. Initially cases were selected with abnormal thyroid swelling with or without physical voice change, difficulty in swallowing, biochemical thyroid function abnormality and lymphadenopathy. In all cases thyroid ultrasound (USG) and Fine Needle Aspiration Cytology (FNAC) was done for initial confirmation of papillary thyroid carcinoma. In all cases biochemical thyroid function tests were conducted. After proper pre anesthetic checkup and adequate counselling we did Radical Thyroidectomy (IRT) with or without selected lymph node excision after taking informed written consent. Patients with abnormal thyroid function were made euthyroid prior to surgery. Appropriate surgical note was preserved including measurement and gross findings of tumor and number of lymph node or groups of lymph node excised with gross findings. Any surgical or post-surgical complications were also noted. All tissues were labeled and preserved in formalin preparation solution and send for final histopathological diagnosis, grading and staging with proper history and physical findings. Patients were kept for observation in hospital up to healing. Total duration of hospital stay was noted. All patients were orally supplemented with Levothyroxine sodium (Euthrox) or Thyroxine. A few cases with suspected residual tumor were sent for radio ablation by using radio Iodine $\left(\mathrm{I}^{131}\right)$. Patients were followed with an interval of 3-6 months by history, physical examination, biochemical thyroid function tests and thyroid USG with any complication. All documents were preserved in a preformed consolidated proforma prepared by our department. Appropriate consent was taken from every patient and from local ethical body to use the data for study. Statistical analysis was performed using SPSS (Statistical Package for Social Sciences) 13.0 (SPSS Inc, Chicago, IL, USA).

\section{RESULTS}

A total 70 patient were included in this study. Among them 55 $(78.6 \%)$ were female and rest 15 were male indicating a female predominance with a 0.27 male to female ratio. Mean age of the patients were 43.81 years. Among them 34 (48.6\%) belonged to the under 45 years age group. Peak incidences were found in the $3^{\text {rd }}, 4^{\text {th }}$ and $5^{\text {th }}$ decades.

Table 1 : Distribution of the study patients by age $(n=70)$.

\begin{tabular}{lcc} 
Age (in years) & Number of patients (n) & Percentage (\%) \\
$11-20$ & 2 & 2.9 \\
$21-30$ & 6 & 8.6 \\
$31-40$ & 19 & 27.1 \\
$41-50$ & 24 & 34.3 \\
$51-60$ & 15 & 21.4 \\
$61-70$ & 4 & 5.7 \\
Mean \pm SD & \multicolumn{3}{|c}{$43.81 \pm 11.4$} \\
Range (min-max) & \multicolumn{3}{c}{$(15-67)$} \\
\end{tabular}

Table 2 : Distribution of the study patients by sign/symptom $(\mathrm{n}=70)$.

\begin{tabular}{lrr} 
Sign/Symptom & n & $\%$ \\
Voice change & 1 & 1.4 \\
Difficulty in swallowing & 2 & 2.9 \\
Lymphadenopathy & 50 & 71.4 \\
\hline
\end{tabular}


Initially patients were selected with palpable nodular swelling of thyroid confirmed by USG, with or without lymphadenopathy and with a FNAC report of suspected thyroid carcinoma. Only 2 patients presented with difficulty in deglutition and 1 patient presented with voice change. A total 16 patients presented with thyroid functional abnormality.

Table 3 : Distribution of the study patients by biochemical examination $(\mathrm{n}=70)$.

\begin{tabular}{llrr} 
Thyroid function tests & & $\mathbf{n}$ & \% \\
\multirow{3}{*}{ T3 } & Low & 1 & 1.4 \\
& High & 2 & 2.9 \\
& Normal & 67 & 95.7 \\
T4 & Low & 2 & 2.9 \\
& High & 3 & 4.3 \\
& Normal & 65 & 92.9 \\
TSH & Low & 3 & 4.3 \\
& High & 10 & 14.3 \\
& Normal & 57 & 81.4
\end{tabular}

Selected patients were treated by Radical thyroidectomy alone or with selected lymph node excision.

Table 4 : Distribution of the study patients by surgery $(n=70)$.

\begin{tabular}{lcr} 
Surgery & n & $\%$ \\
$\begin{array}{l}\text { Radical Thyroidectomy } \\
\text { Radical Thyroidectomy with selected }\end{array}$ & 16 & 22.9 \\
lymph node excision & 54 & 77.1 \\
\hline
\end{tabular}

After operation in most of the cases tumor diameter was measured. A mean diameter of $1.32 \mathrm{~cm}$ was found. During operation findings were as follows-

Table 5 : Distribution of the study patients by longest diameter of tumor $(n=70)$.

\begin{tabular}{lrr}
$\begin{array}{l}\text { Longest Diameter of } \\
\text { Tumor in } \mathbf{c m}\end{array}$ & $\mathbf{n}$ & \% \\
$<1$ & 31 & 44.3 \\
$1.1-2$ & 19 & 27.1 \\
$2.1-3$ & 12 & 17.1 \\
$>3$ & 1 & 1.4 \\
whole thyroid & 1 & 1.4 \\
No record & 6 & 8.6 \\
Mean \pm SD & & $1.32 \pm 1.9$ \\
Range (min,max) & \multicolumn{2}{c}{$(0.05,3.5)$} \\
\hline
\end{tabular}

Table 6 : Distribution of the study patients by lymph node metastasis status $(\mathrm{n}=70)$.

\begin{tabular}{|c|c|c|}
\hline $\begin{array}{l}\text { Histological findings of } \\
\text { lymph node }\end{array}$ & n & $\%$ \\
\hline No metastasis & 41 & 58.6 \\
\hline Central lymph node metastasis & 27 & 38.6 \\
\hline Lateral lymph node metastasis & 2 & 2.8 \\
\hline \multicolumn{3}{|c|}{ Number of lymph node metastasis } \\
\hline Mean \pm SD & & $1.34 \pm 2.28$ \\
\hline Range (min,max) & & $(0,11)$ \\
\hline \multicolumn{3}{|c|}{$\begin{array}{l}\text { Number of lymph node dissected } \\
\text { during operation }\end{array}$} \\
\hline Mean \pm SD & & $5.62 \pm 6.03$ \\
\hline Range (min,max) & & $(0,28)$ \\
\hline
\end{tabular}

Table 7 : Distribution of the study patients by TNM and American Joint Committee on Cancer (AJCC) Staging $(n=70)^{12}$.

\begin{tabular}{|c|c|c|c|c|c|c|}
\hline $\begin{array}{l}\text { TNM } \\
\text { staging } \\
\text { Stage }\end{array}$ & $\begin{array}{l}\text { AJCC } \\
\text { staging } \\
\text { for PTC } \\
\text { n }\end{array}$ & $\%$ & Age & Stage & n & $\%$ \\
\hline TxN0M0 & 1 & 1.4 & $\begin{array}{l}\text { Under } \\
45 \text { Years } \\
\left(\mathrm{n}_{<45}=34\right)\end{array}$ & I & 34 & 48.6 \\
\hline TxNxM0 & 2 & 2.8 & & & & \\
\hline TxN1aM0 & 1 & 1.4 & II & 0 & 0 & \\
\hline T1NxM0 & 5 & 7.1 & & & & \\
\hline T1N0M0 & 15 & 21.4 & $\begin{array}{l}45 \text { Years } \\
\text { and above } \\
\left(\mathrm{n}_{>45}=36\right)\end{array}$ & I & 12 & 17.1 \\
\hline T1N1M0 & 3 & 4.3 & & & & \\
\hline T1N1aM0 & 10 & 14.3 & II & 12 & 17.1 & \\
\hline T2NxM0 & 4 & 5.7 & & & & \\
\hline T2N0M0 & 13 & 18.6 & III & 9 & 12.9 & \\
\hline T2N1M0 & 1 & 1.4 & & & & \\
\hline T2N1aM0 & 12 & 17.1 & IVA & 3 & 4.3 & \\
\hline T3N1bM0 & 1 & 1.4 & & & & \\
\hline T4aNxM0 & 1 & 1.4 & IVB & 0 & 0 & \\
\hline T4aN0M0 & 1 & 1.4 & IVC & 0 & 0 & \\
\hline
\end{tabular}

TNM staging derived from histopathological reports. Though in all cases $M$ is 0 but in 2 cases there is distant metastasis in further clinical and histopathology reports of other tissues. 
Table 8 : Distribution of the study patients by primary outcome $(\mathrm{n}=70)$.

\begin{tabular}{lcr} 
Hospital Stay (days) & $\mathbf{n}$ & $\%$ \\
$5-10$ & 47 & 67.1 \\
$11-15$ & 15 & 21.4 \\
$16-20$ & 4 & 5.7 \\
$>20$ & 4 & 5.7 \\
Mean \pm SD & $10.63 \pm 4.64$ & \\
Range (min,max) & 5,29 & \\
Survival in years & $\boldsymbol{n}$ & $\%$ \\
$\leq 5$ & 31 & 44.3 \\
5 to<10 & 32 & 45.7 \\
$\geq 10$ & 7 & 10 \\
Mean \pm SD & $5.59 \pm 2.64$ & \\
Range (min, max) & 1,10 & \\
Other outcome & $\boldsymbol{n}$ & $\%$ \\
Death within follow-up & 2 & 2.9 \\
Local recurrence & 4 & 5.7 \\
Distant metastasis & 2 & 2.9 \\
Radio ablation by using radio & & 7.1 \\
Iodine (I31) (1 to4) cycle & 5 & 88.6 \\
Thyroid hormone replacement needed & 62 & \\
\hline
\end{tabular}

Table 9 : Distribution of the study patients by secondary outcome $(\mathrm{n}=70)$.

\begin{tabular}{lcc} 
Complications & n & \% \\
Post operative complications & 4 & 5.7 \\
Re opening surgery & 1 & 1.4 \\
Angina pectoris & 1 & 1.4 \\
Breast cancer & 1 & 1.4 \\
Cough for 3 years & 1 & 1.4 \\
Surgery of Thyroid Again & 1 & 1.4 \\
Voice change & 1 & 1.4 \\
No complication & 60 & 85.7 \\
\hline
\end{tabular}

\section{DISCUSSION}

A total 70 patient were included in this study. Peak incidences were found in $3^{\text {rd }}, 4^{\text {th }}$ and $5^{\text {th }}$ decades with a female predominance. Mean age of the patients were 43.81 years (Table 1). Study conducted with 82 cases by Jiafeng Wang et al. in China had similar incidence with female predominance and 48 patients had $<1 \mathrm{~cm}$ tumor diameter ${ }^{13}$. In this study we found the longest diameter of tumor was $<1 \mathrm{~cm}$ in $44.3 \%$ cases and in $44.2 \%$ of cases tumor was $>1-<3 \mathrm{~cm}$ in longest diameter (Table 5). Since 1988 , nearly $50 \%$ of the tumors were $<1 \mathrm{~cm}$ and $87 \%$ were $<2 \mathrm{~cm}^{14}$. Only 1 case had $>3 \mathrm{~cm}$ in longest diameter tumor and 1 case had tumor involving the whole thyroid gland (Table 5). Most of the cases were found in euthyroid state (Table 3). 50 cases $(71.4 \%)$ presented with lymphadenopathy indicating thyroid carcinoma with local metastasis. 1 case presented with voice change indicating compression of the recurrent laryngeal nerve and in 2 cases large swelling caused difficulty in swallowing (Table 2).
$41.4 \%$ dissected lymph node had histopathological evidences of metastasis. Study of Jiafeng Wang et al. in China observed lymph node metastasis in 47 cases out of 82 cases, which is almost similar with this study ${ }^{13}$. In only 2 cases there were distant metastasis though in TNM histopathological staging shows M0 in all cases (Table 4 and 7). A mean of 1.34 lymph node metastasis was found histopthologically and a mean of 5.62 lymph nodes were dissected during operation. Radio ablation was needed in only 5 cases and low numbers $(5.7 \%)$ of local recurrence indicates experience in selection of lymph nodes will result in better outcomes (Table 6,7,8).

All cases under 45 years of age were in stage I according to AJCC staging system and only 3 cases over 45 years were in aggressive staging hence influencing the outcome (Table 7). Occurrence of PTC over and below 45 years were more or less similar with the above mentioned study ${ }^{14}$.

Mean survival of 5.59 years was observed with a standard deviation of 2.64 years and mean hospital stay was around 11 days with a standard deviation of around 5 days (Table 8), indicates excellent cure with prolong survival and minimum morbidity. Probably this excellent survival rate had relation with tumor size, as in most of the cases in this study had small sized tumor. We experienced 5.7\% local recurrence. In United States from 1999-2006, 420 patients were treated with this comprehensive approach, where 5\% experienced local recurrence ${ }^{15}$.

5 patients required Radio ablation by using Radio Iodine $\left(\mathrm{I}^{131}\right)$. One of them needed 4 cycle of therapy. His age was 60 years. We performed revision surgery. In two settings we dissected 25 of his lymph nodes and found metastasis in 5 of them. In death cases local recurrence and distant metastasis was evident and death occurred 1 to 2 years after operation. Thyroid hormone replacement was done by Thyroxine and levothyroxine sodium (Euthrox) as needed by individual patients (Table 8 and 9).

Regarding complications only 4 cases had operative or postoperative complications. In 1 case we had to reopen due to excessive bleeding to find out the bleeding site and for proper hemostasis. 1 patient presenting with breast carcinoma had distant metastasis, 1 patient experienced prolong cough and 1 experienced voice change probably due to recurrent laryngeal nerve damage. We did a revision surgery after recurrence of thyroid swelling after 1 year (Table 9).

\section{ACKNOWLEDGMENTS}

The authors thank the Shandong Province Analysis and Test Center and the participants for their cooperation.

\section{CONCLUSION}

Our experiences in surgical management of papillary thyroid carcinoma evolved in prolonged survival with fewer complications and relatively limited use of radio ablation thus indicating a promising cure rate.

\section{DISCLOSURE}

All the authors declared no competing interest. 


\section{REFERENCES}

1. Udelsman R, Chen H. The current management of thyroid cancer. Adv Surg. 1999; 33: 1

2. Davies L, Welch H. Increasing incidence of thyroid cancer in the United States. 1973-2002. JAMA. 2006; 295: 2164-2167.

3. Sippel RS, Caron NR, Clark OH. An evidence-based approach to familial nonmedullary thyroid cancer: Screening, clinical management, and follow-up. World J Surg. 2007; 31: 924-933.

4. Hemminki K, Eng C, Chen B. Familial risks for nonmedullary thyroid cancer. J Clin Endocrinol Metab. 2005; 90:5747-5753.

5. Gharib H, Papini E, Paschke R, Duick DS, Valcavi R, Hegedus L et al. American Association of Clinical Endocrinologists, Associazione Medici Endocrinologi, and European Thyroid Association medical guidelines for clinical practice for the diagnosis and management of thyroid nodules. J Endocrinol Invest. 2010; 33 Suppl 5: 1-50.

6. Noguchi S, Murakami N, Yamashita H, Toda M and Kawamoto H. Papillary thyroid carcinoma: modified radical neck dissection improves prognosis. Arch Surg. 1998; 133: 276-280.

7. Cooper DS, Doherty GM, Haugen BR, Kloos RT, Lee SL, Mandel SJ et al. Revised American Thyroid Association management guidelines for patients with thyroid nodules and differentiated thyroid cancer. 2009; 19: 1167-1214.

8. Bilimoria KY, Bentrem DJ, Ko CY, Stewart AK, Winchester DP, Talamonti MS et al. Extent of surgery affects survival for papillary thyroid cancer. Ann Surg. 2007; 246: 375-381, discussion 381-374.

9. Sosa JA, Bowman HM, Tielsch JM, Powe NR, Gordon TA and Udelsman R. The importance of surgeon experience for clinical and economic outcomes from thyroidectomy. Ann Surg. 1998; 228: 320-330.

10. Saunders BD, Wainess RM, Dimick JB, Doherty GM, Upchurch GR and Gauger PG. Who performs endocrine operations in the United States? Surgery. 2003; 134: 924-931, discussion 931.

11. Randolph GW, Dralle H, Abdullah H, Barczynski M, Bellantone R, Brauckhoff $\mathrm{M}$ et al. Electrophysiologic recurrent laryngeal nerve monitoring during thyroid and parathyroid surgery: International standards guideline statement. Laryngoscope. 2011; 121 Suppl 1: S1-16.

12. Green F L, Page D L, Fleming I D. Edits-American JointCommittee on Cancer- $6{ }^{\text {th }}$ Publishor-Springer, USA. $2002 ; 8: 78-79$.

13. Wang J, Gu J, Han Q, Wang W, Shang J. Value of intraoperative parathyroid hormone monitoring in papillary thyroid cancer surgery: Can it be used to guide the choice of operation methods? Int J Clin Exp Med. 2015; 8(5): 7778-7785.

14. Hughes D, Haymart M, Miller B, Doherty GM. The most commonly occurring papillary thyroid cancer in the United States is now a micro carcinoma in a patient older than 45years. Thyroid. 2011; 21: 231-236.

15. Grant CS, Stulak JM, Thompson GB,Richards ML, Hay ID. Risks and adequacy of an optimized surgical approach to the primary surgical management of papillary thyroid carcinoma treated during 1999-2006. World J Surg. 2010; 34: 1239-1246. 